\title{
Analysis of Surgical Recurrence after Larynx Microsurgery for Benign Lesions
}

\author{
Maria Theresa Costa Ramos de Oliveira Patrial ${ }^{10}$ Rogério Hamerschmidt ${ }^{10}$ \\ Jorge Eduardo Fouto Matias ${ }^{1 \oplus}$ Evaldo Dacheux de Macedo Filho ${ }^{1 \odot}$ Bettina Carvalho ${ }^{1 \odot}$ \\ ${ }^{1}$ Department of Surgical Clinics, Hospital de Clínicas, Universidade \\ Federal do Paraná, Curitiba, PR, Brazil \\ Int Arch Otorhinolaryngol 2021;25(4):e496-e503. \\ Address for correspondence Maria Theresa Costa Ramos de Oliveira \\ Patrial, MD, Rua Deputado Heitor Alencar Furtado, 3001, \\ apartamento 1801, Mossunguê, Curitiba, PR, 81200-110, Brazil \\ (e-mail: mtheresa_ramos@yahoo.com.br).
}

\begin{abstract}
Introduction The study of larynx lesions is of great importance. More than $50 \%$ of people with vocal complaints have benign vocal fold alterations and some require surgery.

Objective To determine which factors are related to surgical recurrence of benign laryngeal lesions and to determine which videolaryngoscopic diagnoses are related to the risk or protection of surgical relapses over time.

Methods Observational, analytical, cross-sectional study with retrospective data collection of 1,383 surgeries in 1,301 patients.

Results The mean age at the first surgery was 39.2 years old. The predominant gender was female (65.6\%).

There were 396 cases of polyps (25.34\%), 349 cases of cysts (22.33\%), 261 cases of Reinke edema (16.7\%), 175 cases of nodules (11.2\%), 153 cases of minor structural alterations (MSAs) (9.79\%), 94 cases of leukoplakia (6.01\%), 77 cases of granulomas (4.93\%) and 58 cases of pseudocysts (3.71\%). The age presented statistical significance with the risk of surgical relapses $(p=0.016)$. Male gender was associated with the greatest chance of relapse.

Diagnosis of granuloma $(p<0.001)$ and of leukoplakia $(p<0.001)$ were associated with a higher risk of surgical recurrence. Cyst diagnosis was associated with protection $(p=0.015)$ in relation to the chance of further surgeries. Patients with associated lesions, bilaterals or voice professionals did not present a statistically significant association with surgical recurrence.

Keywords

- larynx

Conclusion Age and gender are statistically related to the increase of surgical

- microsurgery

- vocal cords relapses. Leukoplakia and granuloma are associated with increased surgical relapses. Patients submitted to cyst microsurgery appear to be protected against surgical recurrence.
\end{abstract}

\section{Introduction}

The study of benign lesions of the larynx is of great importance for the knowledge of otorhinolaryngologists due to the high frequency and the impact they cause in the quality of life of the patients. When these lesions do not respond to drug therapy and/or phonotherapy, the option of treatment is surgical. received

October 7, 2019

accepted

August 13, 2020

published online

November 30, 2020
DOI https://doi.org/ 10.1055/s-0040-1718529. ISSN 1809-9777.

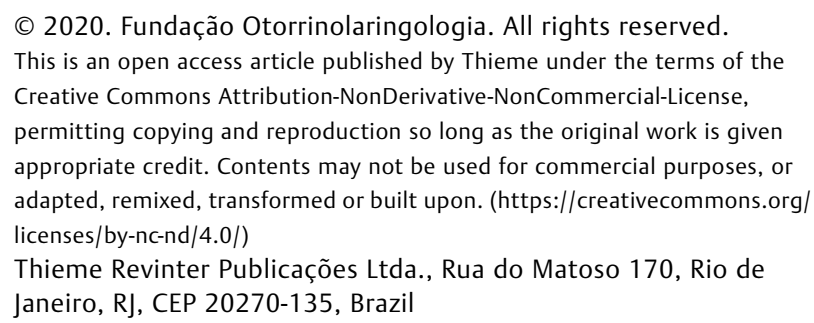

(c) 2020. Fundação Otorrinolaringologia. All rights reserved. This is an open access article published by Thieme under the terms of the Creative Commons Attribution-NonDerivative-NonCommercial-License, permitting copying and reproduction so long as the original work is given appropriate credit. Contents may not be used for commercial purposes, or adapted, remixed, transformed or built upon. (https://creativecommons.org/ licenses/by-nc-nd/4.0/) Thieme Revinter Publicações Ltda., Rua do Matoso 170, Rio de Janeiro, RJ, CEP 20270-135, Brazil 
It is observed that $>50 \%$ of people with vocal complaints present benign alteration of the vocal fold epithelium and a large part of these lesions require surgical treatment. The aim of surgery in patients with benign lesions of the larynx is to increase the phonatory function and/or to establish the anatomopathological diagnosis through biopsy. ${ }^{1}$

In the past 25 years, from a deeper knowledge of the etiopathogenesis and pathophysiology of vocal fold diseases, there was a great development of phonomicrosurgery, making an increasingly effective performance in the treatment of vocal lesions possible. This treatment modality, therefore, is of great relevance for collective health. ${ }^{2}$

Microsurgery or fibrosurgery remains the viable and often initial treatment for patients requiring rapid and definitive results. ${ }^{3}$

To monitor the success of the surgical treatment of these lesions, it is necessary to know the target population, which lesions are most frequently submitted to fibrosurgery, the percentage of recurrences of these lesions and recurrent surgeries.

To support the present study, epidemiological studies were taken into account. These are of great importance for the analysis and description of the health problems and can point out the causes and guide the indication of the means of control and prophylaxis.

The objectives of the present study were to determine which factors are related to the risk of recurrent surgical relapses of benign lesions over time and to determine which videolaryngoscopic diagnoses are related to the risk or to the protection of surgical relapses.

The present study was approved by the scientific ethics committee under the protocol number 1.709.890.

\section{Methods}

An observational, analytical, cross-sectional study with retrospective data collection of patients submitted to laryngeal microsurgery between January 2000 and January 2018 in a private otorhinolaryngological hospital.

The present study was approved by the Human Ethics Committee of the referenced hospital, under the number 1,709,890 and CAAE 58087516.6.0000.5529.

Considering the associative nature of cross-sectional studies, we studied the independent variables: voice, gender, age, association of lesions, diagnosis and laterality in relation to the chance of surgical relapses.

The exclusion criteria were: patients with insufficient data in the electronic medical record, patients with irregular lesions, patients with malignant lesions and patients with laryngeal papillomatosis.

We studied 1,301 patients submitted to laryngeal microsurgery with benign lesions of the larynx, grouped into 8 groups: polyp, nodule, Reinke edema, leukoplakia, granuloma, cyst, pseudocyst and minor structural alterations (MSAs).

Patients with vocal sulcus, vasculodysgenesia, micromembranes and mucosal bridges were grouped in the MSA group.
Patients with contact ulcer or ulcerated granuloma were considered to belong to the granuloma group.

Voice professionals were considered as the voice users of Koufman Levels I and II. ${ }^{4}$

The tabulated data were sent for a statistical study. Each variable was analyzed according to the time until the occurrence of the first surgical relapse, to study the risk of new surgeries.

The results of quantitative variables were described by medians, minimum values and maximum values. For categorical variables, frequencies and percentages were presented. The gender-age comparison was analyzed using the Student $t$-test. Regarding the diagnoses, the comparisons were made by the chi-squared test. Considering that the patients had different follow-up times, for the analysis of factors associated with relapses, regression models were adjusted considering the times to relapses. A first analysis was performed considering the risk of relapse from the first surgery. For this, Cox regression models were adjusted, and the Wald test was used to evaluate the significance of the variables. Kaplan-Meier curves were presented to describe the times until the first relapse occurred. ${ }^{5}$

The association measure presented was the hazard ratio (HR) with 95\% confidence intervals (CIs). The proportionality of the risks was analyzed by the Shoenfeld waste. Values of $p<0.05$ indicated statistical significance. The data were analyzed using the Stata/SE v.14.1 software. (StataCorp LP, College Station, TX, USA).

\section{Results}

The following analysis was performed based on 1,383 surgeries in 1,301 patients. A total of 1,232 patients underwent 1 surgery; 62 patients, 2 surgeries; 5 patients, 3 surgeries; 1 patient, 5 surgeries and 1 patient underwent 7 surgeries. The mean age of the patients in the $1^{\text {st }}$ surgery was 39.2 years old. There was a predominance of females with $65.6 \%$, versus $34.4 \%$ of males. Of the patients with data present in the electronic medical record, a total of 1,149 patients, $27.8 \%$ were voice professional patients. A little more than half of the patients (52.2\%) presented lesions affecting the 2 vocal folds. Of the total number of surgeries, $74.1 \%$ of the patients had single lesions and $25.9 \%$ had 2 or more associated lesions. To facilitate the statistical analysis of the lesions studied, it was decided to group the lesions into 8 groups: polyps, cysts, MSAs, pseudocysts, nodules, granulomas, leukoplakia and Reinke edema. Of these 8 groups of lesions, 1,563 were found in the 1,383 surgeries evaluated. This number is greater than the number of surgeries due to the fact that the same patient could have one or more lesions.

There were 396 cases of polyps (25.34\%), 349 cases of cysts (22.33\%), 261 cases of Reinke edema (16.7\%), 175 cases of nodules (11.2\%), 153 cases of MSAs (9.79\%), 94 cases of leukoplakia (6.01\%), 77 cases of granulomas (4.93\%) and 58 cases of pseudocysts (3.71\%).

- Table 1 shows the distribution of relapses related to the diagnosis. It is observed that, of the total number of polyps, there were only 20 recurrent cases. It is noted that 12 cases 
Table 1 Distribution of lesions in patients who had surgical recurrences

\begin{tabular}{|l|l|l|}
\hline Recurrent Diagnosis & $\mathbf{n}$ & \% \\
\hline Polyp & 20 & 29 \\
\hline Granuloma & 12 & 17.4 \\
\hline Leukoplakia & 12 & 17.4 \\
\hline Reinke edema & 8 & 11.6 \\
\hline Nodule & 7 & 10 \\
\hline Cyst & 6 & 8.7 \\
\hline MAS & 3 & 4.3 \\
\hline Pseudocyst & 1 & 1.4 \\
\hline TOTAL & 69 & 100 \\
\hline
\end{tabular}

Abbreviation: MSA, minor structural alteration.

of granuloma presented recurrences (15.6\%), as well as 12 cases of leukoplakia (12.8\%). It can also be seen in - Table 1 that only 6 cases of vocal cysts presented recurrence (1.72\%).

Patients had different follow-up times ranging from 0 to 210 months ( 17.5 years). Therefore, the relapse analysis was performed considering the time elapsed until the first recurrence (for patients who had relapse) or follow-up times until the last visit (for patients who did not have a relapse).

-Fig. 1 shows the Kaplan-Meier curve for the time elapsed until the first recurrence. It is observed that, over time, the cases of patients who do not need to undergo a new surgery are reduced.

For the analysis of the association of the variables age, gender, associated lesion, laterality of the lesion and professional voice, with relapse, Cox regression models were adjusted and Wald tests were used to evaluate the signifi- cance of each variable. Initially, for each of these variables, the null hypothesis was tested that the times until the first recurrence are equal for the two classifications of the variable, versus the alternative hypothesis of different times (univariate analysis).

-Table 2 presents the $p$-values of the statistical tests (univariate and multivariate) and the estimated HR with respective 95\% CIs estimated from the adjustment of the multivariate model.

It was observed that the variables associated lesion in the first surgery, laterality and professional voice were not significantly associated with the time elapsed until the first recurrence.

The age of the patient in the $1^{\text {st }}$ surgery presented statistical significance in the univariate analysis. Each year the older one implies an increase in the risk of the patient having a recurrence $(p=0.016)$. In the presence of the other variables (multivariate model), it tends to be significant ( $p=0.096)$.

Regarding the gender variable, both the univariate analysis $(p<0.001)$ and the multivariate analysis $(p=0.001)$ found an association between this variable and recurrence. It can be said that, independently of the other variables included in the model, gender is significantly associated with the time elapsed until the first relapse.

It can be seen in - Fig. $\mathbf{2}$ that male patients present a more unfavorable time curve until the first recurrence than female patients.

In - Fig. 3, Kaplan-Meier curves for the association of lesions appear to be practically parallel over time. That is, having two or more lesions does not increase the risk of the patient of having another surgery.

In - Fig. 4, the Kaplan-Meier curves according to the laterality of the lesions also present similar paths over time. For unilateral lesions or bilateral lesions, there is no statistical significance for the risk of surgical relapse.

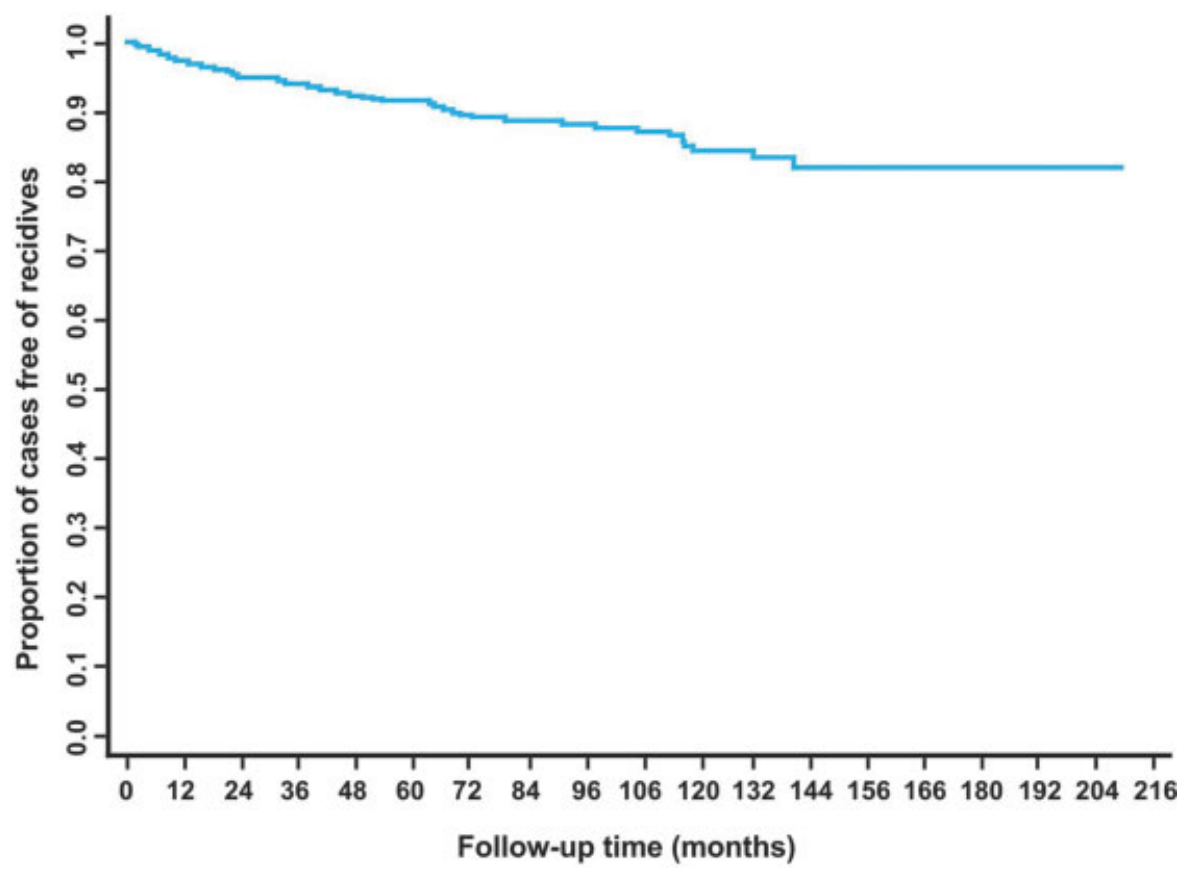

Fig. 1 Kaplan-Meier curve for the proportion of relapse-free patients over time. 
Table 2 Variables and respective univariate and multivariate statistical analyzes

\begin{tabular}{|l|l|l|l|l|}
\hline Variable & $\boldsymbol{p}^{*}$ value (univariate) & $\boldsymbol{p}^{*}$ value (multivariate) & HR & IC 95\% \\
\hline Age (years old) & 0.016 & 0.096 & 1.01 & $0.99-1.03$ \\
\hline Gender & $<0.001$ & 0.001 & 2.54 & $1.49-4.31$ \\
\hline Associated lesions at first surgey & 0.746 & 0.319 & 0.76 & $0.44-1.30$ \\
\hline Uni or bilateral at first surgery & 0.881 & 0.383 & 1.28 & $0.74-2.20$ \\
\hline Voice professional & 0.070 & 0.283 & 0.73 & $0.41-1.30$ \\
\hline
\end{tabular}

Abbreviation: HR, hazard ratio.

${ }^{*}$ Cox regression model and Wald test, $p<0,05$.

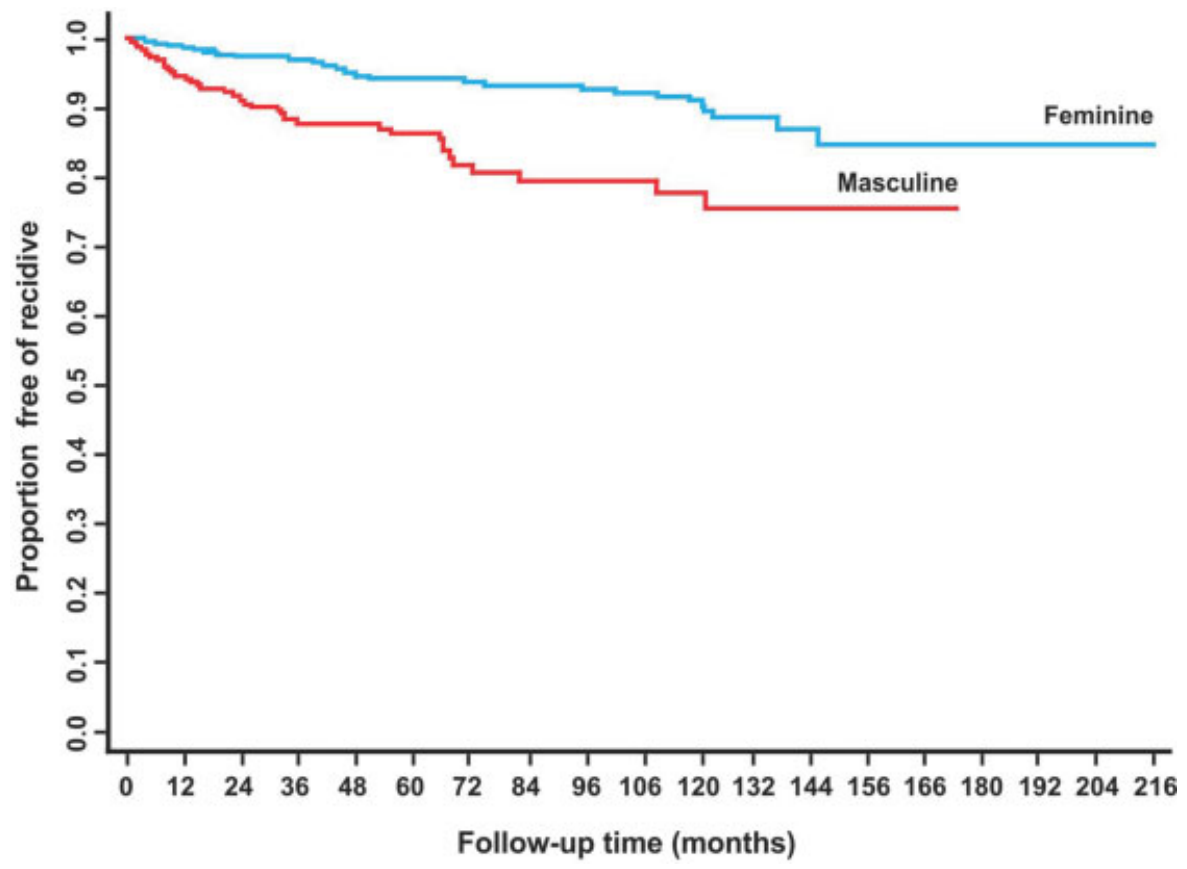

Fig. 2 Kaplan-Meier curve for the proportion of relapse-free patients over time according to gender.

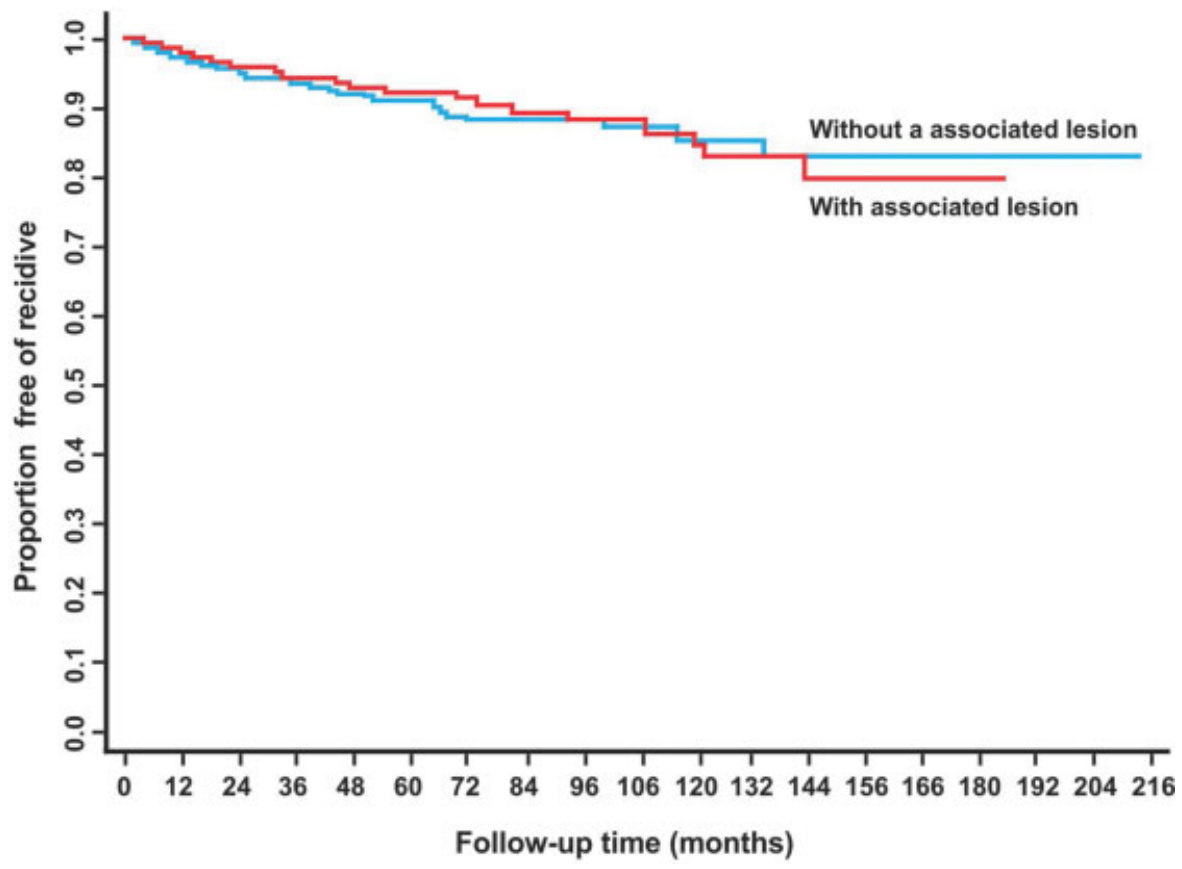

Fig. 3 Kaplan-Meier curve for the proportion of relapse-free patients over time according to associated lesions. 


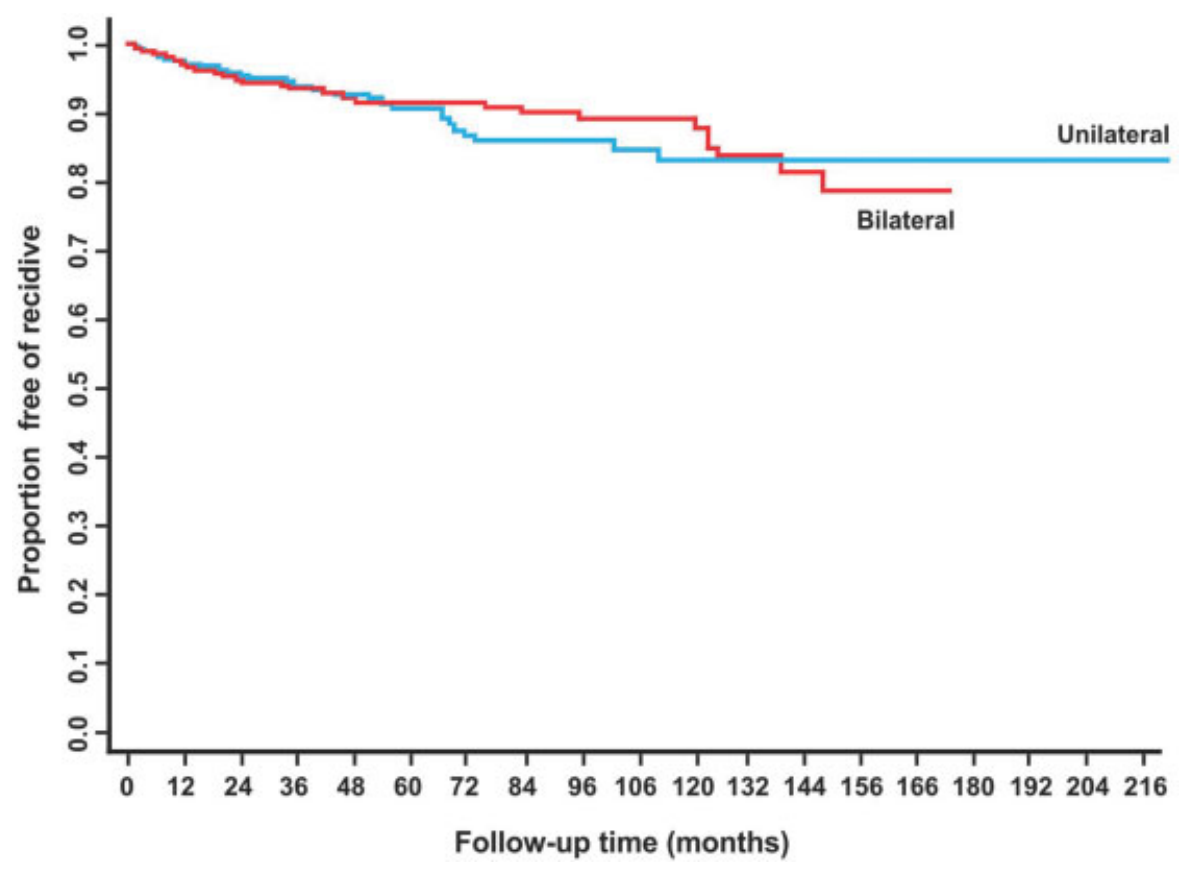

Fig. 4 Kaplan-Meier curve for the proportion of relapse-free patients over time according to laterality.

In the univariate analysis, professional voice patients have a tendency to have fewer recurrences $(p=0.070)$ than nonvoice professionals. However, in a multivariate analysis, in which the other variables were considered, there was no statistically significant difference. - Fig. 5 shows the KaplanMeier curves according to the profession and the risk of recurrence over time.

Reinke edema, MSAs, granuloma, leukoplakia, pseudocyst, and nodule were adjusted for each of the diagnoses of the first surgery (isolated or associated) of polyps, cyst, Reinke edema, the significance of the association between the diagnosis and the risk of relapse (or time to relapse).
Thus, for each of the diagnoses, the null hypothesis was tested that the times until the first relapse are equal for cases with and without the diagnosis, versus the alternative hypothesis of different times. - Table 3 shows the $p$-values of the statistical tests, in a univariate analysis for the risk of relapse.

The diagnoses of granuloma $(p<0.001)$ and leukoplakia $(p<0.001)$ were significantly associated with the risk of recurrence. The diagnosis of cysts is associated with protection $(p=0.015)$ in relation to the risk of relapse as seen in the Kaplan-Meier curve ( - Fig. 6 ). Considering that patients with a concomitant diagnosis of cyst, granuloma and leukoplakia

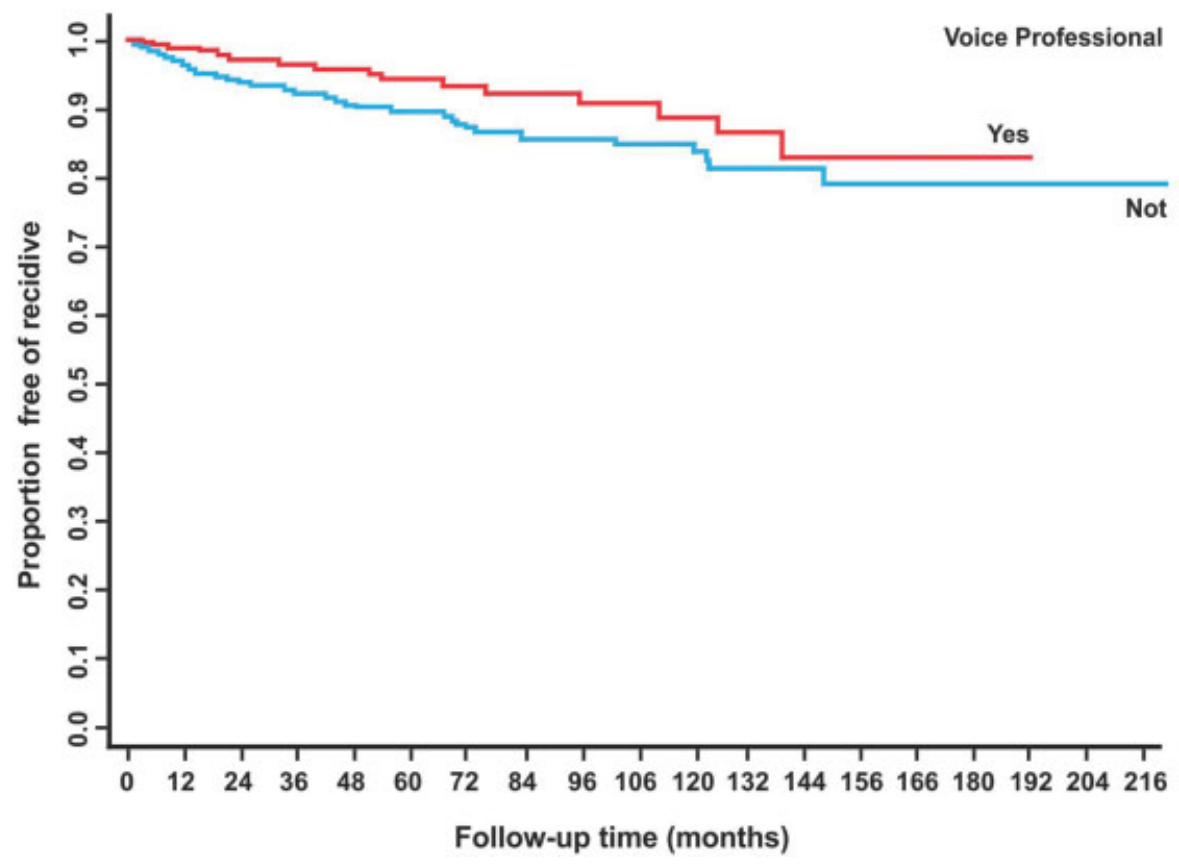

Fig. 5 Kaplan-Meier curve for the proportion of relapse-free patients over time according to profession. 
Table 3 -values in univariate analysis for the risk of relapse of the different diagnoses

\begin{tabular}{|l|l|}
\hline Variable & $\boldsymbol{p}^{*}$ value (univariate) \\
\hline Polyp & 0.705 \\
\hline Cyst & 0.015 \\
\hline Reinke Edema & 0.190 \\
\hline MSA & 0.743 \\
\hline Granuloma & $<0.001$ \\
\hline Leucoplakia & $<0.001$ \\
\hline Pseudocyst & 0.203 \\
\hline nodule & 0.119 \\
\hline
\end{tabular}

Abbreviation: MAS, minor structural alteration.

${ }^{*}$ Cox regression model and Wald test, $p<0,05$.

were not observed in the first surgery, a single "diagnostic" variable was considered with four possible classifications: cyst, granuloma, leukoplakia and others. From this variable, a Cox model was adjusted, and these two-to-two classifications were compared (univariate analysis). In - Fig. 6, the Kaplan-Meier curves are then presented for each of the diagnoses considered.

\section{Discussion}

This seems to be the first study comparing the risk of surgical recurrence among microsurgery due to benign lesions of the vocal folds.

Although the treatment of benign vocal lesions can be individualized according to clinical judgment, the present study argues that the best treatment for most benign vocal lesions is laryngeal microsurgery. However, it is known that conservative treatment can be reserved for patients with vocal nodules. ${ }^{6}$

In disagreement with the reports of Lehmann et al. and Kleinsasser, in which laryngeal microsurgery was performed mostly in men, in the present study women corresponded to $65.6 \%$ of operated patients. ${ }^{7,8}$ This result is similar to that found by the study by Dailey, which reports the incidence of female gender in $62 \%$ of operated patients. ${ }^{9}$ This incidence also agrees with the findings of Perazzo et al. ${ }^{10}$

Regarding age, the mean value found for patients in the present study was concentrated in the age group that corresponds to the economically active population (39.2 years old), with a standard deviation (SD) of 14.2 years. Representing great economic and social impact. These findings are similar to those of Perazzo et al., Lehmann et al. and Kleinsasser. ${ }^{7,8,10}$

Hah et al., different from the present study, did not find differences in the prevalence of laryngeal diseases between men and women, but found that vocal complaints are more frequent in women. The same authors emphasize that vocal alterations and dysphonia are more common in the elderly due to vocal muscle atrophy, thinning of vocal cord elastic fibers and degeneration of mucous glands. ${ }^{11}$

In the present study, the rate of patients with bilateral lesions diagnosed preoperatively, by videolaryngoscopy, was $52.2 \%$. In the literature, Poels et al. reported a incidence of bilateral lesions of $82 \%$, but these were diagnosed intraoperatively. ${ }^{12}$ Similar to the literature, Cho et al. found a rate of $72.8 \%$ of contralateral reactional lesions in patients with benign lesions of vocal folds who underwent mechanical surgery. The authors also demonstrated that the presence of contralateral lesions is related to worsening of vocal quality and should be approached surgically, especially if speech therapy and vocal rest are not feasible in the postoperative period. ${ }^{3}$

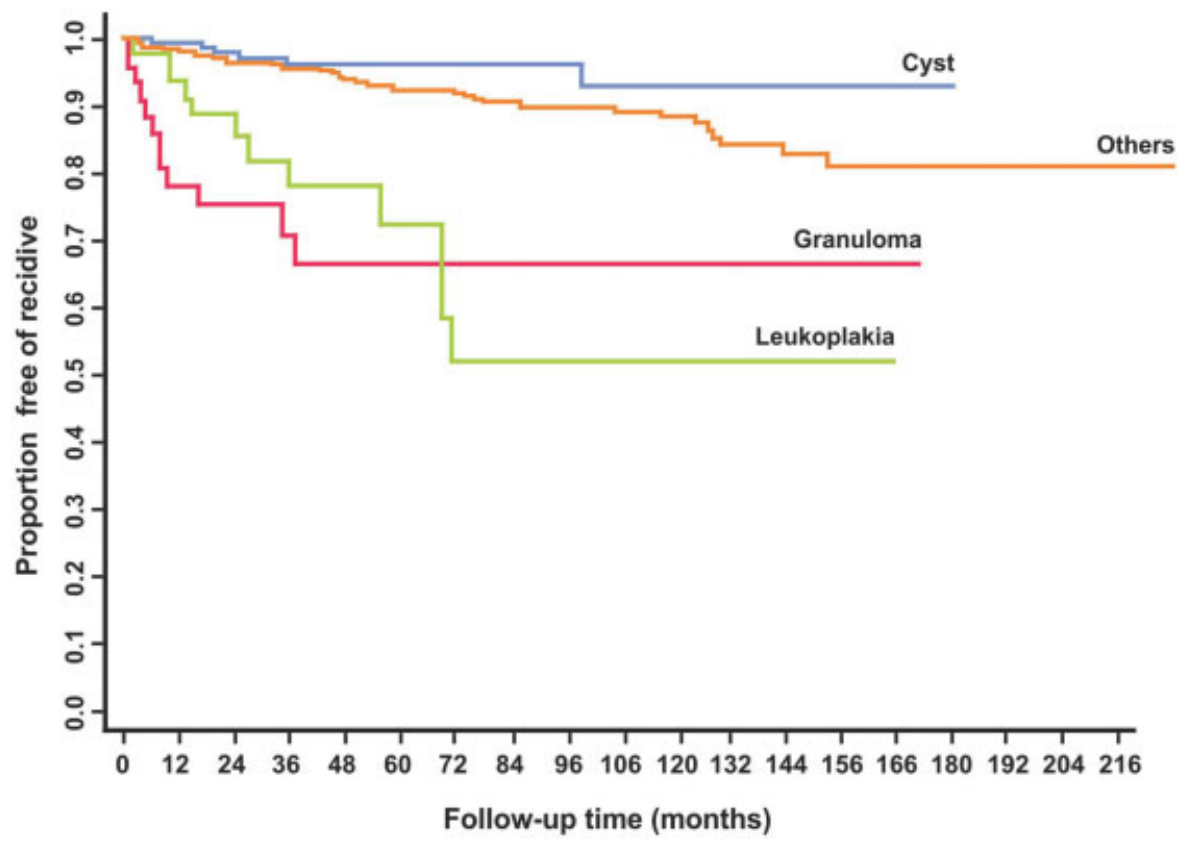

Fig. 6 Kaplan-Meier curve for the proportion of relapse-free patients over time according to the diagnosis. 
Zhukhovitskaya et al. also argue that some benign lesions of the vocal folds are associated with age and gender. Nodules and pseudocysts are more common in young women, and Reinke edema in older women. Hemorrhagic polyps, contact ulcers, leukoplakia, and sulcus occur more frequently in men. These prevalences can be explained by differences in the laryngeal anatomy and phonatory physiology, as well as by the ability of vocal fold layers to absorb fonotrauma. These differences may have implications for clinical or surgical outcomes. ${ }^{13}$

Although the variables gender and age may have been confounding factors in the present study, the observation that revision surgeries may be more common in males and in older patients is valid considering the anatomical changes and that may occur in the vocal folds. In subsequent studies, the two most recurrent diagnoses (granuloma and leukoplakia) can be excluded and a reanalysis of the remaining population performed.

The most common lesion in the present study was vocal polyp, which was found 396 times among the patients studied (25.34\%), in agreement with the reports of Haas et al., Lehmann et al. and Kleinsasser, in which polyps were the main indication for laryngeal microsurgery. ${ }^{7,8,14}$ Phaniendra Kumar et al., in a series of 75 lesions evaluated during the surgical procedure, found an incidence of $56 \%$ of polyps. ${ }^{15}$ Vocal polyps may be related to smoking, pollution and vocal abuse. ${ }^{16}$ However, similar to Ju et al., the present study did not find statistical significance for new surgeries due to vocal polyps. ${ }^{17}$

Intracordal cysts were the most frequent lesions found in the study by Perazzo et al. ${ }^{10}$ However, in the present study, cysts were the second most prevalent (22.33\%). In the reports by Kleinsasser and by Abrol et al., the presence of cysts was reported in only 5.52 and $3.5 \%$ of the patients, respectively. ${ }^{8,18}$ The large variation of the findings reflects the diagnostic difficulty of this pathology, and the diagnosis be performed intraoperatively. Even with the difficulty of removing the vocal cysts, the rates of surgical recurrence are low and, in the present analysis, the microsurgeries in a patient with cyst in the vocal folds demonstrated protection against the risk of surgical relapses. Another explanation for the low rate of surgical recurrence of vocal cysts would be the fact that the origin of vocal cysts is not related to vocal abuse or laryngeal irritants. Huang et al. did not find statistical significance between the rates of recurrence of the lesion at 3 months of follow-up. ${ }^{19}$ Chang et al., evaluating the unusual surgical technique for removal of the retention vocal cysts, found recurrence of the lesion in only 1 patient of the 21 operated ones. $^{20}$

Reinke edema was the third most frequent lesion in the present study, appearing 261 times (16.7\%). These results are above those described by Kleinsasser, who found $10 \%$, and by Hass et al., who found $10.14 \%$. Lehmann et al. report an incidence of Reinke edema of $\sim 16.5 \%$. ${ }^{7,8,14}$ The results above contrast with those reported by Bouchayer et al., who reported an incidence of Reinke edema of $6 \% .{ }^{21}$ Even with the persistence of the structural alterations after the reintroduction by Reinke edema, there was no statistically significant relationship for new surgeries due to this lesion in the present study.

There were 175 cases of vocal nodules $(11.2 \%)$, the $4^{\text {th }}$ highest incidence, similar to that found by Mossallam et al., who in a series of 106 lesions found nodules in $9 \%$ of cases. ${ }^{22}$ Bouchayer et al. found nodules in $24 \%$ of cases in a series of 1283 patients. ${ }^{21}$ In the study by Dailey et al., vocal nodules were the most prevalent lesions. ${ }^{9}$ It is important to note that most patients with vocal nodules are treated with speech therapy, with surgical indication in cases that do not evolve adequately with this treatment. In our series, microsurgery due to vocal nodules had no relation to surgical relapse over the years. However, some authors have demonstrated that, despite surgical treatment, vocal nodules are associated with a high rate of recurrence. ${ }^{23}$ There are few articles in the literature about the long-term results and the rate of recurrence of vocal nodal treatment. Béquignon et al. observed a $30 \%$ recurrence of dysphonia and the presence of new benign lesions in $18 \%$ of the patients submitted to microsurgery for vocal nodules. They also found that speech therapy in the postoperative period is associated with lower rates of recurrence of the lesion. ${ }^{24}$ In an isolated or associated way, the present study did not find statistical significance between the diagnosis of nodules in the first surgery and the risk of surgical relapse.

Leukoplakia was found 94 times (6.01\%), similar to the findings of Lehmann et al., with $6.60 \%$, being the highest incidence in the series studied. ${ }^{7}$ In a retrospective study, Phaniendra Kumar et al. reported leukoplakia in 3 patients $(4.28 \%){ }^{15}$ This was an incidence similar to that found by Herrington-Hall et al., who reported leukoplakia in $4.1 \%$ of the patients. ${ }^{25}$ In the present study, the diagnosis of leukoplakia had a statistically significant relationship with the appearance of surgical relapses over the years. This can be explained by the histopathological characteristics inherent to this type of lesion.

Granuloma was found 77 times (4.93\%). This result is above those of Bouchayer et al. and Herrington-Hall et al., who found an incidence of $1 \%$, and below that of Mossallam et al., who report an incidence of 7\%. ${ }^{21,22,25}$ Lehmann et al. report an incidence of 5\%, approximately the same as the one found in the present study. ${ }^{7}$ In the series by Kumar et al., the incidence was $6 \%$. In the present study, a statistically significant relationship was observed between the appearance of granulomas and the risk of surgical relapses over the years. This finding may be due to the irritative factors known to cause granulomas, which, if persistent, may facilitate the recurrence of such injuries. Carroll et al. found a 67\% recurrence rate of granulomas in patients submitted to cold excision without other associated procedures. The rate of surgical recurrence of laryngeal granulomas in the present study was $14.29 \%{ }^{26}$ However, adjuvant procedures such as corticosteroid injection or botulinum toxin are not known. been performed in the patients studied here. Despite the relatively low recurrence rate of the present study, when compared with the study by Carroll et al., it was found that the rate of surgical relapses of granulomas is statistically significant when compared with the other rates of 
microsurgery due to benign lesions of the vocal folds. Havas et al found a success rate in $50 \%$ of the 16 patients with granulomas who underwent surgical excision. ${ }^{27}$ De Lima Pontes et al. found a recurrence rate of $38 \%$ of surgically removed granulomas, with all patients receiving adjuvant corticosteroid injection therapy. ${ }^{28}$

Pseudocyst was found in 58 cases (3.71\%). This result is below that found by Bouchayer et al., who reported pseudocysts in $6 \%$ of operated patients. The Bouchayer et al. series was the only one found to include pseudocysts as a diagnostic item. ${ }^{21}$

Miaśkiewicz et al., evaluating patients with vocal grooves, considered that the preoperative diagnosis of this vocal alteration is difficult, even when videolaryngostroboscopy was performed. The diagnosis is sometimes made only intraoperatively. ${ }^{29}$ Cases of MSA, despite the diagnostic difficulty and variety of patient recovery and rehabilitation in the postoperative period, were not related to the risk of surgical relapse in the present study.

\section{Conclusion}

The factors that are statistically related to the increase in surgical relapses over time are age and gender.

The risk of surgical relapse over time is increased in patients submitted to microsurgery for granuloma or leukoplakia. Patients submitted to microsurgery for vocal cysts appear to have protection in relation to the risk of surgical relapse.

Note

The present paper was presented as the final project for a master's degree at the Universidade Federal do Paraná.

\section{Conflict of Interests}

The authors have no conflict of interests to declare.

\section{References}

1 Noordzij JP, Woo P. Glottal area waveform analysis of benign vocal fold lesions before and after surgery. Ann Otol Rhinol Laryngol 2000;109(05):441-446

2 Vasconcelos SJ, Caldas Neto SdaS. New system of instrument stabilization in laryngeal microsurgery. Rev Bras Otorrinolaringol (Engl Ed) 2010;76(05):643-648

3 Cho JH, Choi YS, Joo YH, Park YH, Sun DI. Clinical Significance of Contralateral Reactive Lesion in Vocal Fold Polyp and Cyst. J Voice 2018;32(01):109-115

4 Koufman JA. Approach to the patient with a voice disorder. Otolaryngol Clin North Am 1991;24(05):989-998

5 Kleinbaum DG. Kaplan-Meier Survival Curves and the Log-Rank Test. In: Kleinbaum DG, Klein M. Survival Analysis: a selflearning text. 3.ed. New York, NY: Springer; 2012:55-96

6 Rosen CA, Gartner-Schmidt J, Hathaway B, et al. A nomenclature paradigm for benign midmembranous vocal fold lesions. Laryngoscope 2012;122(06):1335-1341

7 Lehmann W, Pampurik J, Guyot JP. Laryngeal pathologies observed in microlaryngoscopy. ORL J Otorhinolaryngol Relat Spec 1989;51(04):206-215
8 Kleinsasser O. [Microlaryngoscopy and endolaryngeal microsurgery. II: A review of 2500 cases (author's transl)]. HNO 1974;22 (03):69-83

9 Dailey SH, Spanou K, Zeitels SM. The evaluation of benign glottic lesions: rigid telescopic stroboscopy versus suspension microlaryngoscopy. J Voice 2007;21(01):112-118

10 Perazzo PSL, Cota AC, Moura MPC, Almeida WLC, Gois CRT. Pre and Post-Operative Conditions of Patients Who Underwent Laryngeal Microsurgery for the Main Benign Lesions. Rev Bras Otorrinolaringol (Engl Ed) 2000;66(05):507-510

11 Hah JH, Sim S, An SY, Sung MW, Choi HG. Evaluation of the prevalence of and factors associated with laryngeal diseases among the general population. Laryngoscope 2015;125(11): 2536-2542

12 Poels PJ, de Jong FI, Schutte HK. Consistency of the preoperative and intraoperative diagnosis of benign vocal fold lesions. J Voice 2003;17(03):425-433

13 Zhukhovitskaya A, Battaglia D, Khosla SM, Murry T, Sulica L. Gender and age in benign vocal fold lesions. Laryngoscope 2015;125(01):191-196

14 Haas E, Döderlein K. [Endolaryngeal microsurgery. A report of our experiences in the years from 1966 to 1976 (author's transl)]. Laryngol Rhinol Otol (Stuttg) 1978;57(03):235-242

15 Phaniendra Kumar V, Srinivasa Murthy M, Ravikanth S, Kumar R. Phonomicrosurgery for benign vocal Fold lesions - our experience. Indian J Otolaryngol Head Neck Surg 2003;55(03):184-186

16 Cecatto SB, Costa KA, Garcia RID, Haddad L, Angelico FV Junior, Rapaport PB. Vocal cord polyps: clinical and surgical aspects. Rev Bras Otorrinolaringol 2002;68(04):534-538

17 Ju YH, Jung KY, Kwon SY, et al. Effect of voice therapy after phonomicrosurgery for vocal polyps: a prospective, historically controlled, clinical study. J Laryngol Otol 2013;127(11):1134-1138

18 Abrol BM, Natarajan PR. Endolaryngeal microsurgery. Indian J Otolaryngol Head Neck Surg 1976;28(03):126-128

19 Huang Y, Xia S, Chen J, Huang Z, Luo C, Chen F. [Effects of two surgical techniques for vocal cord cyst]. Lin Chung Er Bi Yan Hou Tou Jing Wai Ke Za Zhi 2009;23(03):119-121

20 Chang HP, Chang SY. An alternative surgical procedure for the treatment of vocal fold retention cyst. Otolaryngol Head Neck Surg 2003;128(04):470-477

21 Bouchayer M, Cornut G. Microsurgery for benign lesions of the vocal folds. Ear Nose Throat J 1988;67(06):446-449, 452-454, 456-464 passim

22 Mossallam I, Kotby MN, Ghaly AFEA. Histopathological aspects of benign vocal fold lesions associates with dysphonia. In: Kirchner JA, editor. Vocal Fold Histopathology: A symposium. San Diego: College-Hill; 1986:65-80

23 Pedersen M, McGlashan J. Surgical versus non-surgical interventions for vocal cord nodules. Cochrane Database Syst Rev 2012;13 (06):CD001934

24 Béquignon E, Bach C, Fugain C, et al. Long-term results of surgical treatment of vocal fold nodules. Laryngoscope 2013;123(08): 1926-1930

25 Herrington-Hall BL, Lee L, Stemple JC, Niemi KR, McHone MM. Description of laryngeal pathologies by age, sex, and occupation in a treatment-seeking sample. J Speech Hear Disord 1988;53(01):57-64

26 Carroll TL, Gartner-Schmidt J, Statham MM, Rosen CA. Vocal process granuloma and glottal insufficiency: an overlooked etiology? Laryngoscope 2010;120(01):114-120

27 Havas TE, Priestley J, Lowinger DS. A management strategy for vocal process granulomas. Laryngoscope 1999;109(2 Pt 1):301-306

28 de Lima Pontes PA, De Biase NG, Gadelha EC. Clinical evolution of laryngeal granulomas: treatment and prognosis. Laryngoscope 1999;109(2 Pt 1):289-294

29 Miaśkiewicz B, Szkiełkowska A, Piłka A, Skarżyński H. Results of surgical treatment in patients with sulcus vocalis. Otolaryngol Pol 2015;69(06):7-14 